\title{
Riscos Psicossociais de um Contexto Laboral da Vigilância Sanitária: Estudo Qualitativo
}

\author{
Guilherme Delavald ${ }^{1}$ iD , Liciane Diehl ${ }^{2}$ \\ Universidade do Vale do Taquari - UNIVATES, Lajeado, RS, Brasil
}

\begin{abstract}
Resumo: Riscos psicossociais são todos aqueles agentes laborais com os quais o indivíduo convive no dia a dia e que são percebidos de maneira negativa pelo próprio trabalhador, afetando a sua saúde. 0 presente estudo, de abordagem qualitativa, teve como objetivo analisar os principais riscos psicossociais do contexto laboral de servidores públicos do Setor de Vigilância Sanitária de um município do interior do Rio Grande do Sul (RS). Participaram oito trabalhadores e utilizou-se, como técnica de coleta de dados, entrevistas semiestruturadas. A análise dos resultados deu-se por análise de conteúdo, que gerou cinco categorias a posteriori: sentidos do trabalho; conteúdo e organização do trabalho; ritmos e tempos de trabalho; liderança e avaliação de desempenho; e fatores de proteção. Considerações são apontadas tendo em vista que, quando medidas preventivas precoces são adotadas em relação ao risco psicossocial, podese obter uma redução considerável nos custos econômicos e sociais, tanto para o trabalhador quanto para o empregador.
\end{abstract}

Palavras-chave: riscos psicossociais, saúde mental e trabalho, saúde ocupacional, gestão pública

\section{Psychosocial Risks of Sanitary Surveillance Work Context: Qualitative Study}

\begin{abstract}
Psychosocial risks are all those labor agents that the individual lives with on a daily basis and that are perceived in a negative way by the worker himself, affecting his health. The present study, with a qualitative approach, aimed to identify and analyze the main psychosocial risks in the work context of public servants in the Health Surveillance Sector from a countryside city of Rio Grande do Sul. Eight workers participated and semi-structured interviews were used as a data collection technique. The results were analyzed by content analysis, which generated five categories: meanings of work; work content and organization; rhythms and working hours; leadership and performance evaluation; and protective factors. Considerations are pointed out in view that, when early preventive measures are adopted in relation to psychosocial risk, a considerable reduction in economic and social costs can be obtained, both for the worker and for the employer and employers.
\end{abstract}

Keywords: psychosocial risks, mental health and work, occupational health, public management

1 Administrador de Empresas pela Universidade do Vale do Taquari - UNIVATES. Servidor Público. Lajeado-RS, Brasil.E-mail: gdelavald2@universo.univates.br

2 Doutora em Psicologia Clínica pela UNISINOS, Mestra em Psicologia Social pela PUCRS, Pós-graduada em Gestão Estratégica de Pessoas pela UNIVATES e Psicóloga pela UNISINOS. Atualmente é professora e Coordenadora do curso de Psicologia e da Especialização em Psicologia Organizacional e do Trabalho da UNIVATES. Lajeado-RS, Brasil. E-mail: licidiehl@gmail.com

Submetido em: 03/02/2021. Primeira decisão editorial: 08/04/2021. Aceito em: 27/05/2021. 


\section{Introdução}

Ao longo das últimas décadas do século $\mathrm{XX}$, o contexto mercadológico em nível mundial vem sofrendo grandes mudanças, em virtude da facilidade no acesso e da troca de informações, além da intensificação da competitividade. Isso repercute nas mais variadas áreas: econômica, política, no âmbito jurídico e também na esfera empresarial, tanto de empresas públicas, como privadas (Feitosa \& Lima, 2016).

De acordo com Hirata (2015), essas mudanças podem ocasionar efeitos na saúde dos trabalhadores, em virtude das pressões que sofrem no ambiente laboral e da competitividade a que estão submetidos. De acordo com Baumann, Muijen e Gaebel (2010), as doenças ocupacionais acometem não apenas aos trabalhadores e seus familiares, mas também às instituições onde eles trabalham, através da diminuição da produtividade, e a sociedade como um todo, em função dos custos que são produzidos. A cada 15 segundos, no mundo, algum trabalhador vem a falecer em consequência de alguma doença relacionada ao trabalho. Além disso, morrem 2,02 milhões de pessoas por ano, em função de doenças que possuem relação com o trabalho (OIT, 2014).

Veloso Neto (2015) afirma que os riscos psicossociais estão cada vez mais presentes no espaço laboral. Esses são definidos como os aspectos do contexto organizacional, que podem gerar prejuízos físicos ou psicológicos aos trabalhadores. Costa e Santos (2013) enfatizam que é crescente a preocupação pelos riscos psicossociais em ambientes laborais, devido ao seu aumento, que justifica-se pelas mudanças que ocorrem no mercado de trabalho, especialmente pelas novas formas de se fazer gestão, pela natureza do trabalho e também pelas alterações socioeconômicas. Os autores acrescentam, ainda, que as exigências emocionais que a função exercida exige, as inseguranças que o emprego causa, a ausência de autonomia, a carga horária exercida e os conflitos entre equipes de trabalho são fatores potenciais aos riscos psicossociais.

De acordo com Alves et al. (2009), nas organizações, especialmente privadas, muito se fala em qualidade de vida e em fatores que desencadeiam eventos estressantes aos trabalhadores. Percebe-se, porém, que existem poucos estudos que trabalham esse mesmo tema junto ao Poder Público. Em atinência, Ramminger e Nardi (2007) afirmam ainda que as políticas públicas que dizem respeito à saúde dos trabalhadores são focadas aos funcionários da iniciativa privada, deixando, dessa maneira, uma lacuna voltada à saúde dos empregados e servidores públicos.

Por outro lado, as oportunidades de emprego no setor público, há anos, vêm sendo muito disputadas, sendo que o número de inscritos em concursos são a prova disso. No concurso realizado pela prefeitura do município em que envolve o presente estudo, no ano de 2018, foram deferidas 8.190 inscrições e 2.690 indeferidas, o que soma mais de 10 mil candidatos interessados nas vagas oferecidas no setor público. Um dos fatores que torna o serviço público atrativo é a diferença salarial, se comparado com a iniciativa privada.

No início de 2019, o jornal Correio Braziliense publicou um artigo voltado à economia que apresenta números comprovando que entre os anos de 2007 a 2017, a diferença salarial entre os dois setores aumentou consideravelmente. Em 2007, os servidores públicos recebiam $72 \%$ a mais do que os profissionais assalariados do setor privado, isto é, àquele cujo vínculo empregatício se dá através da Consolidação das Leis do Trabalho (CLT). Já em 2017, esse percentual cresceu para $87 \%$. É importante salientar que essa diferença aparece em todos os níveis de escolaridade.

Desta forma, considerando como parâmetros a estabilidade e a remuneração, poderia se supor que os servidores se sentem satisfeitos com o seu trabalho. Entretanto, essa informação não condiz com a realidade, pois, de acordo com Balassiano et al. (2011), existem vários estressores nos ambientes públicos, especialmente intrínsecos ao trabalho e relacionados ao papel do indivíduo na organização.

O setor público está presente nas mais diversas esferas da sociedade, seja por meio da conservação de bens públicos ou na manutenção de serviços oferecidos aos contribuintes. Um destes setores é a Vigilância Sanitária, a qual foi criada no município que envolve este estudo no ano de 1998 
e, desde então, vem normatizando os produtos e serviços que circulam na cidade.

\section{Afinal, quem é o Servidor Público?}

De acordo com Marcondes (2016), é possível diferenciar os servidores públicos em três grupos diferentes, sendo eles: estatutários, empregados públicos e servidores temporários. Servidores estatutários são as pessoas contratadas por meio de concurso público, tornando-se titulares do cargo. Os servidores estatutários estão submetidos a legislação específica dos Municípios, Estados ou União. A forma de contratação em regime estatutário pode estar relacionada à administração direta, ou seja, o servidor representa, dentro do cargo, a posição do poder público.

O autor complementa que, diferente dos servidores estatutários, os empregados públicos executam as atividades conforme o queé determinado na Consolidação das Leis do Trabalho (CLT). Em outras palavras, entende-se que os empregados públicos são colaboradores de empresas de direito privado, porém subordinadas à administração pública.

Já os servidores públicos por tempo determinado, são pessoas que substituem os titulares dos cargos públicos por tempo determinado. A forma mais comum de contrato temporário são as substituições por licenças: saúde, doença de pessoa da família, ou outra licença estabelecida em lei. A seleção, salvo exceções é feita por meio de processo seletivo simplificado, em que o servidor contratado trabalha até o retorno do titular do cargo (Marcondes, 2016).

De acordo com Domingues Júnior (2005), as estruturas que voltam-se à manutenção da saúde dos servidores é bastante defasada, sendo que uma das consequências disso é o fato de que os históricos de saúde doença dos servidores estatutários são maiores do que os do Regime Geral de Previdência. Além disso, o autor complementa ainda que no ano de 2004, os índices de aposentadorias por invalidez de servidores públicos chegaram a $27,3 \%$, número bastante elevado.

Essa circunstância de doença saúde dos servidores públicos faz com que a mão de obra das empresas e órgãos públicos percam a eficiência dos serviços prestados, gerando assim, perdas econômicas e financeiras.

A Vigilância em Saúde (VISA) que contemplou o presente estudo abrange ações de fiscalização, promoção, prevenção e controle de doenças e agravos à saúde. Dentre os componentes do setor, cita-se: a vigilância epidemiológica, a vigilância ambiental, a vigilância da saúde do trabalhador e a vigilância sanitária. No organograma da Secretaria da Saúde do município, a VISA, assim como os demais componentes, está vinculada à Atenção Básica.

Sendo assim, a VISA conta com uma equipe multidisciplinar formada por Médicos Veterinários, Enfermeiros, Nutricionista, Farmacêutico(a) e equipe administrativa, possuindo capacidade técnica para atuar nas mais diversas áreas do setor regulado. $A$ forma de contratação dos profissionais de Vigilância Sanitária é por meio de concurso público e a designação para o exercício da função de fiscal se dá por meio de portaria.

\section{Contexto da Pesquisa}

O município em questão tem população estimada, no ano de 2018, de 82.951 (IBGE), formada sobretudo por descendentes de imigrantes italianos e alemães. Ainda segundo dados do IBGE, mais de $99 \%$ da população vive em área urbana. A economia do município é baseada na indústria, comércio e serviços (Instituto Brasileiro de Geografia e Estatística [IBGE], 2018).

O trabalho da VISA consiste no conjunto de ações capazes de diminuir, eliminar ou prevenir riscos à saúde, desenvolvidas no que diz respeito à produção e circulação de bens, e também na prestação de serviços de interesse à saúde. Ela adota uma postura educativa e construtiva, objetivando sempre a regularização dos estabelecimentos e o aprimoramento dos produtos e serviços ofertados à população. De caráter fiscalizatório, perante situações de não conformidade que coloquem em risco à saúde pública de forma grave, por vezes se faz necessário tomar as medidas legais cabíveis.

Utilizando 2016 como ano base, foram licenciados 1.202 estabelecimentos/serviços, sendo 
que as licenças sanitárias são expedidas mediante inspeção prévia, com a finalidade de averiguação das reais condições sanitárias. Esta sistemática de licenciamento objetiva reduzir os transtornos gerados a partir da falta de cumprimento das normas sanitárias que acabam por expor os munícipes a riscos de saúde.

No ano de 2017, manteve-se essa sistemática, priorizando as inspeções sanitárias nos estabelecimentos que, de acordo com a atividade econômica desenvolvida, possam oferecer maior risco à população. No primeiro semestre do mesmo ano, o setor de Vigilância Sanitária implantou um programa de ações voltadas à educação sanitária, participando de grupos nas Estratégias de Saúde da Família e elaborando palestras voltadas às agentes comunitárias de saúde. 0 projeto também é voltado às crianças da rede municipal de ensino, objetivando a construção de consciência sanitária.

Considerando a importância das ações de vigilância sanitária como forma de prevenção de agravos da saúde da população, acredita-se que as ações voltadas a saúde destes profissionais são fundamentais, visto o impacto das suas atividades laborais no contexto onde atuam.. Além disso, dentre o rol de atividades da VISA, cita-se ainda, as ações conjuntas com conselhos de classe, Polícia Federal e Ministério Público. As parcerias com outros órgãos são de grande importância e fortalecem as ações já existentes.

Assim, o presente estudo tem a finalidade de analisar os principais riscos psicossociais do contexto laboral de servidores públicos do Setor de Vigilância Sanitária de um município localizado no interior do Rio Grande do Sul, uma vez que é um setor de relevância para a comunidade local, devido às ações de fiscalização, promoção, prevenção e controle de doenças e agravos à saúde.

O órgão tem envolvimento com mais de três mil estabelecimentos comerciais, como restaurantes, bares, salões de beleza, petshops, farmácias, entre outros, os quais dependem da sua autorização para funcionar. A eficácia de um setor como a Vigilância Sanitária é importante para a economia da cidade, bem como a viabilidade das empresas que, conforme atividade econômica, são submetidas a inspeções sanitárias. O não funcionamento adequado de setores como esse, podem influenciar negativamente e até mesmo inviabilizar uma empresa ou um profissional autônomo estabelecido no município.

\section{Saúde Mental e Trabalho}

De acordo com Vasques-Menezes (2012), em 1802 , foi normatizada a primeira lei do parlamento britânico, no que diz respeito ao labor, intitulada como "Lei de saúde e moral dos aprendizes". Em seguida, no ano de 1833, foi instaurada a Factury Act, isto é, leis trabalhistas aprovadas pelo Parlamento do Reino Unido, com o intuito de controlar as condições de emprego industrial. Essas ações preconizaram maior atenção à saúde do trabalhador e atuação da medicina social.

No Brasil, o cuidado com relação à saúde dos trabalhadores, a partir de 1934, foi um compromisso do Ministério do Trabalho e, a partir da Constituição de 1988, passou a fazer parte também das atribuições da Previdência Social e do Ministério da Saúde (Vasques-Menezes, 2012). Em 1943, foi sancionada pelo então presidente Getúlio Vargas a Consolidação das Leis Trabalhistas (CLT), cujo objetivo é a regulamentação das relações coletivas e individuais do trabalho (Rio de Janeiro capital, 1943).

Em análise mais recente, as primeiras décadas do século XXI foram marcadas por um crescente desenvolvimento social. Para tanto, houve um grande avanço em áreas do conhecimento relacionadas às doenças psicológicas. $O$ antigo modelo Biomédico de saúde levava em consideração principalmente os fatores biológicos, deixando de lado os aspectos como o processo de adaptação e a relação do homem com o espaço e com o trabalho. Assim, surgia uma nova corrente teórica multicausal, que procurava identificar não só as características biológicas, mas também as sociais, ligadas ao processo de saúde-doença (Ferraz, 1997).

$\mathrm{O}$ autor complementa ainda que, com o avanço dos estudos, novas teorias sobre o processo de saúde-doença foram surgindo e o próprio conceito sofreu modificações, cuja adaptação também está intimamente ligada ao próprio modo 
de vida das pessoas. Neste sentido, considerando as questões relacionadas aos vínculos entre trabalho e saúde/doença mental, este estudo fundamentase na abordagem teórico-metodológia relativa às teorias sobre o estresse, conforme Jacques (2003). Segundo a autora, nesta perspectiva, ao identificar os estressores, as ações de prevenção estão voltadas para o gerenciamento dos trabalhadores, o coping, e intervenções pontuais como mudanças cognitivocomportamentais, sendo que a maioria destas intervenções é apresentada em programas de qualidade de vida no trabalho (QVT).

\section{Riscos Psicossociais do Trabalho}

Os riscos psicossociais do trabalho dizem respeito à dimensão organizacional, isto é, onde pode haver a interferência das condições de trabalho, que podem prejudicar a saúde dos trabalhadores, sobretudo psicologicamente.

Gil-Monte (2012) salienta que os fatores psicossociais são condições presentes em situações laborais relacionadas não apenas com a organização, como um todo, mas também com relação ao cargo exercido, às tarefas realizadas e também ao entorno do espaço em que os indivíduos ou trabalhadores estão inseridos.

O autor complementa que os fatores psicossociais podem favorecer ou prejudicar a atividade laboral e a respectiva qualidade de vida no trabalho das pessoas. No primeiro caso, os fatores psicossociais fomentam o desenvolvimento dos indivíduos, enquanto que quando são desfavoráveis prejudicam a saúde e bem-estar.

De acordo com Veloso Neto (2015), os riscos psicossociais do trabalho correspondem à viabilidade de acontecerem situações prejudiciais e danosas à saúde física, social e mental dos trabalhadores, ocasionadas no ambiente em que estão inseridas profissionalmente. Nesse contexto, Penido e Perone (2013) apontam que:

Os fatores psicossociais têm o potencial de influir de maneira decisiva no bemestar físico e mental do trabalhador, pois podem ocasionar uma diminuição do nível de saúde do ser humano. Esses fatores de risco nunca se apresentam no entorno do meio ambiente laboral isoladamente, mas se interatuam de forma a potencializar os efeitos nocivos. As inúmeras doenças relacionadas à organização, aos processos e ambientes de trabalho apresentam graves riscos à integridade e à saúde física e mental dos trabalhadores. (Penido \& Perone, 2013, p. 36)

Diante do exposto, compreende-se que os riscos psicossociais não dizem respeito a um ambiente de trabalho estabelecido, apenas. Mais do que isso, torna-se oportuno atentar-se também aos aspectos subjetivos envolvidos. Diante desse panorama, Guimarães (2013) afirma que os riscos psicossociais:

[...] podem, também, serem entendidos como as percepções subjetivas que o trabalhador tem dos fatores de organização do trabalho. Como exemplo de fatores psicossociais, pode-se citar: considerações relativas à carreira, à carga e ritmo laboral e ao ambiente social e técnico do trabalho. A "percepção" psicológica que o indivíduo tem das exigências do trabalho é o resultado das características físicas da carga, da personalidade do indivíduo, das experiências anteriores e da situação social do trabalho. (Guimarães, 2013, p. 274)

O autor considera, ainda, que os riscos psicossociais não provocam danos apenas nos sujeitos, mas consequentemente geram efeitos nas organizações, tais como aumento dos índices de absenteísmo. Ou seja, um padrão habitual de ausências no ambiente de trabalho, possíveis acidentes de trabalho, além do aumento considerável da diminuição do rendimento das atividades exercidas.

\section{Classificação dos Riscos Psicossociais}

Veloso Neto (2015) apresenta as dimensões e respectivos fatores de risco, conforme Quadro 1, que segue. 
Quadro 1

Dimensões de fatores de risco psicossocial

continua

\begin{tabular}{|c|c|}
\hline $\begin{array}{l}\text { Dimensões } \\
\text { de fatores de } \\
\text { risco }\end{array}$ & Fatores de risco tipo \\
\hline \multirow{3}{*}{$\begin{array}{l}\text { Relações } \\
\text { laborais }\end{array}$} & $\begin{array}{l}\text { Aumento da vulnerabilidade do } \\
\text { mundo de trabalho num contexto } \\
\text { globalização (crises econômicas, } \\
\text { instabilidade do mercado de trabalho, } \\
\text { liberalização da legislação laboral, } \\
\text { Lean production, outsourcing etc.) }\end{array}$ \\
\hline & $\begin{array}{l}\text { Relações laborais precárias (trabalho } \\
\text { temporário, trabalho informal } \\
\text { involuntário, prestação de serviços } \\
\text { continuada, desclassificação } \\
\text { profissional, subretribuição etc.) }\end{array}$ \\
\hline & $\begin{array}{l}\text { Sentimento de insegurança e } \\
\text { desvalorização no emprego (falta de } \\
\text { perspectivas de emprego, carreira e } \\
\text { desenvolvimento profissional) }\end{array}$ \\
\hline \multirow{5}{*}{$\begin{array}{l}\text { Ritmos e } \\
\text { tempos de } \\
\text { trabalho } \\
\text { (Stresse) }\end{array}$} & $\begin{array}{l}\text { Sobrecarga de trabalho e/ou de } \\
\text { responsabilidades }\end{array}$ \\
\hline & Envelhecimento da força laboral \\
\hline & Aumento dos horários de trabalho \\
\hline & Trabalho por turnos \\
\hline & Intensificação dos ritmos de trabalho \\
\hline \multirow{6}{*}{$\begin{array}{l}\text { Conteúdo e } \\
\text { Organização do } \\
\text { trabalho }\end{array}$} & $\begin{array}{l}\text { Pouca autonomia e controlo das } \\
\text { atividades }\end{array}$ \\
\hline & $\begin{array}{l}\text { Falta ou inadequação de } \\
\text { equipamentos e recursos de trabalho }\end{array}$ \\
\hline & $\begin{array}{l}\text { Reduzidas exigências intelectuais } \\
\text { (subutilização de competências) }\end{array}$ \\
\hline & $\begin{array}{l}\text { Impossibilidade de participação nos } \\
\text { processos de tomada de decisão } \\
\text { operacionais }\end{array}$ \\
\hline & $\begin{array}{l}\text { Trabalho repetitivo/monótono e } \\
\text { trabalho estático }\end{array}$ \\
\hline & $\begin{array}{l}\text { Condições ambientais de trabalho } \\
\text { (ruído, vibrações, radiações, fraca } \\
\text { iluminação etc.) }\end{array}$ \\
\hline $\begin{array}{l}\text { Trabalho } \\
\text { emocional }\end{array}$ & $\begin{array}{l}\text { Elevadas exigências afetivas e } \\
\text { envolvimento emocional }\end{array}$ \\
\hline \multirow{2}{*}{$\begin{array}{l}\text { Conciliação } \\
\text { entre esferas } \\
\text { da vida }\end{array}$} & $\begin{array}{l}\text { Dificuldades de conciliação entre vida } \\
\text { profissional, pessoal e familiar }\end{array}$ \\
\hline & $\begin{array}{l}\text { Desrespeito das exigências da } \\
\text { maternidade, paternidade e cuidado } \\
\text { de pessoas dependentes }\end{array}$ \\
\hline
\end{tabular}

Quadro 1

Dimensões de fatores de risco psicossocial conclusão

\begin{tabular}{|c|c|}
\hline $\begin{array}{l}\text { Igualdade no } \\
\text { trabalho e } \\
\text { emprego }\end{array}$ & $\begin{array}{l}\text { Discriminação no acesso a } \\
\text { oportunidades, no tratamento e na } \\
\text { retribuição (recrutamento, progressão } \\
\text { na carreira, gap salarial) }\end{array}$ \\
\hline \multirow{4}{*}{$\begin{array}{l}\text { Relações } \\
\text { sociais de } \\
\text { trabalho }\end{array}$} & Nível baixo ou elevado de conflito \\
\hline & Práticas de assédio moral \\
\hline & Práticas de assédio sexual \\
\hline & Práticas de bullying \\
\hline \multirow{5}{*}{$\begin{array}{l}\text { Liderança e } \\
\text { Avaliação de } \\
\text { Desempenho }\end{array}$} & Liderança agressiva \\
\hline & Falta de apoio e solidariedade \\
\hline & $\begin{array}{l}\text { Ambiguidade na definição de } \\
\text { objetivos e funções }\end{array}$ \\
\hline & $\begin{array}{l}\text { Inexistência de sistema de avaliação } \\
\text { de desempenho }\end{array}$ \\
\hline & $\begin{array}{l}\text { Instrumentalização de objetivos de } \\
\text { desempenho }\end{array}$ \\
\hline \multirow{4}{*}{$\begin{array}{l}\text { Participação } \\
\text { das/os } \\
\text { trabalhadoras/ } \\
\text { es }\end{array}$} & $\begin{array}{l}\text { Inexistência de mecanismos de } \\
\text { consulta e participação }\end{array}$ \\
\hline & $\begin{array}{l}\text { Inexistência de estruturas de } \\
\text { representação das/os trabalhadoras/es }\end{array}$ \\
\hline & Fraca cultura negocial \\
\hline & $\begin{array}{l}\text { Estrutura de comunicação } \\
\text { organizacional deficitária }\end{array}$ \\
\hline \multirow{2}{*}{$\begin{array}{l}\text { Saúde geral } \\
\text { das/os } \\
\text { trabalhadoras/ } \\
\text { es }\end{array}$} & $\begin{array}{l}\text { Problemas de saúde não decorrentes } \\
\text { do trabalho }\end{array}$ \\
\hline & $\begin{array}{l}\text { Consumo de substâncias psicoativas } \\
\text { (álcool, drogas, etc.) }\end{array}$ \\
\hline
\end{tabular}

Fonte: Veloso Neto, 2015

Estudos brasileiros têm demonstrado que alguns dos fatores de risco apontados por Veloso Neto (2015) têm afetado a saúde de trabalhadores (Loureiro et al., 2008, Oliveira et al., 2013; Oliveira, 2007), como o trabalho emocional, conciliação entre esferas da vida, liderança e avaliação de desempenho e participação das/os trabalhadoras/es. Por isso, serão aprofundados a seguir.

\section{Trabalho Emocional}

O trabalho emocional constitui-se de estado de intenso estresse, que tanto pode ser físico, como emocional, estimulado em virtude das exigências demasiadas do trabalho. Cabe ressaltar que isso acontece quando os trabalhadores identificam que 
os recursos que possuem não são mais suficientes para encarar o que é imposto no ambiente de trabalho. Isto é, o colaborador se dá conta de que o seu conhecimento, habilidades e experiência não são mais suficientes para atender as exigências do contexto organizacional (Tamayo, 2002).

No que diz respeito às consequências da exaustão emocional, o autor diz que:

[...] podem ser observadas nos níveis individual e organizacional. Do ponto de vista individual, a exaustão emocional afeta: a saúde da pessoa, causando numerosos distúrbios psicossomáticos e depressão; as relações interpessoais fora do trabalho, principalmente no seio da família e também no grupo social do trabalhador; e o comportamento, provocando reações como alcoolismo, uso de drogas, agressividade e irritabilidade agravante do trabalho emocional, com impactos no bem-estar subjetivo e psicológico, está relacionada ao fato de que nem sempre os afetos a serem exibidos estão em sintonia com o que efetivamente o empregado está sentindo em dado momento. (Tamayo, 2002, p. 27)

Nesse contexto, vários podem ser os efeitos nocivos ocasionados em virtude do trabalho emocional, tais como utilização de substâncias psicoativas, uso em demasia de bebidas alcoólicas, intensas dores de cabeça, além do aumento dos níveis de absenteísmo (Assunção, 2007).

\section{Conciliação entre Esferas da Vida}

Conforme Sanjutá e Barham (2005), os indivíduos que possuem múltiplas atividades, tais como dividir o seu tempo entre trabalho e família, precisam equilibrar as respectivas demandas e, além disso, organizar a rotina que contemplem o envolvimento com a profissão exercida e a família. Entretanto, vários são os funcionários que se encontram nessa circunstância e que não têm o apoio necessário, principalmente no ambiente de trabalho.

Essas situações podem gerar níveis médios ou até mesmo altos de estresse. Como consequência, podem diminuir o desempenho laboral e desgastar as relações familiares, ocasionando objeções como distúrbios alimentares, ansiedade e até mesmo, depressão.

Os autores acrescentam que com a finalidade de diminuir as divergências, torna-se necessário que os sujeitos criem estratégias para administrar o tempo e o estresse, tanto no âmbito da organização em que se trabalha, como no que diz respeito à vida pessoal e familiar - é importante mencionar que a empresa/instituição possui caráter decisivo na diminuição dos conflitos.

\section{Liderança e Avaliação de Desempenho}

Moscovici (2011) conceitua que líder é um sujeito que em uma organização possui posição de responsabilidade no sentido de gerenciar as atividades em determinado setor ou ambiente de trabalho. Silva e Fernandes (2018) acrescentam que a maneira como o líder se manifesta no que diz respeito aos subordinados ou equipe de trabalho é um fator determinante para que o ambiente seja agradável, de forma que os colaboradores sejam comprometidos e eficazes. Assim, quando o líder se posiciona de forma agressiva, os trabalhadores sentem-se insatisfeitos e inseguros, o que interfere no desempenho destes. Em contrapartida, aumentam-se os fatores estressores e as ausências no trabalho.

Feitosa e Lima (2016) explicam que uma maneira de medir a satisfação e motivação dos colaboradores é através da avaliação de desempenho, ou seja, uma metodologia que tem como finalidade estabelecer uma ligação entre a empresa e os funcionários no sentido de se alcançar os resultados almejados pela empresa. Por meio dessa avaliação, é possível dar feedbacks, ou seja, oferecer um retorno sobre o trabalho do indivíduo, destacando os pontos positivos e as oportunidades de melhoria.

Para tanto, é imprescindível que haja um grau acentuado de confiança entre os líderes e respectivos funcionários, que necessitam ser reconhecidos e integrados nas equipes onde trabalham para que seja possível alcançar os objetivos das empresas e o desempenho almejado (Kawai, 2017). 


\section{Participação das/os Trabalhadoras/es:}

Os modelos de trabalho de algumas organizações podem ocasionar diminuição da autoestima e motivação para exercer a atividade. Isso pode acontecer quando elas - rotineiramente - limitam os verdadeiros talentos e aptidões das pessoas, isto é, quando os colaboradores não têm voz e o seu trabalho não é visto como significativo e proveitoso, o que faz sentire-se, dessa maneira, diminuídos (Limongi-França \& Rodrigues, 2014).

Para Tamayo (2008), quanto maior o espaço dos funcionários em participar do processo de tomada de decisão das organizações, maior é a satisfação e os níveis de envolvimento, além da sensação de bem-estar. Por outro lado, a privação em participar e expor a opinião acerca das decisões, é vista como um demasiado estressor.

Assim, é possível citar a importância do gerenciamento de recursos humanos (GRH), sendo o GRH colaborador o modelo de gestão de Recursos Humanos cujo foco é humanístico, ou seja, no valor que os empregados possuem para a empresa, já que são vistos como participantes dos processos, sendo inovadores e criativos (Júnior et al., 2012).

\section{Procedimentos Metodológicos}

Trata-se de uma pesquisa descritiva, de abordagem qualitativa, já que buscou pelo significado dos dados, cuja base está na compreensão dos fatos, dentro do contexto em que se encontram (Malhotra, 2006). O autor complementa que a descrição qualitativa não interpreta apenas a aparência dos fatos, mas também a essência, explicando, dessa forma, a origem, as correspondências e as mudanças, procurando entender as respectivas consequências.

Os participantes do estudo foram todos os servidores públicos do setor de Vigilância Sanitária, totalizando oito sujeitos, referidos como E1, E2, E3, E4, E5, E6, E7 e E8, com a finalidade de manter preservadas as identidades. A caracterização do perfil dos servidores é apresentada no Quadro 2.

Quadro 2

Caracterização do perfil dos servidores

\begin{tabular}{|l|l|l|l|l|l|l|}
\hline Entrevistado & Sexo & \multicolumn{1}{|c|}{ Idade } & Escolaridade & \multicolumn{1}{|c|}{ Estado Civil } & \multicolumn{1}{c|}{ Cargo } & \multicolumn{1}{c|}{ Tempo na função } \\
\hline E1 & F & 58 & Superior & Casada & Professora & 1 ano e 8 meses \\
\hline E2 & F & 38 & Pós Graduação & Casada & Nutricionista & Nove meses \\
\hline E3 & F & 46 & Pós Graduação & Casada & Enfermeira & 3 anos e 8 meses \\
\hline E4 & F & 40 & Pós Graduação & Casada & $\begin{array}{l}\text { Farmacêutica } \\
\text { (Coordenadora } \\
\text { do setor) }\end{array}$ & 7 anos e 8 meses \\
\hline E5 & F & 32 & Pós Graduação & Solteira & Nutricionista & 1 ano e 10 meses \\
\hline E6 & M & 41 & Pós Graduação & Casado & $\begin{array}{l}\text { Médico } \\
\text { Veterinário }\end{array}$ & 2 anos e 2 meses \\
\hline E7 & F & 60 & Pós Graduação & Divorciada & $\begin{array}{l}\text { Médica } \\
\text { Veterinária }\end{array}$ & 21 anos \\
\hline E8 & M & 28 & Pós Graduação & União Estável & $\begin{array}{l}\text { Agente } \\
\text { Administrativo }\end{array}$ & 4 anos e 6 meses \\
\hline
\end{tabular}

Inicialmente, contatou-se a coordenadora do setor de Vigilância Sanitária para averiguar a possibilidade de realização da pesquisa. Após, o projeto foi encaminhado ao Núcleo Municipal de Educação em Saúde 
Coletiva para análise e, na sequência, o mesmo foi aprovado por meio de emissão de carta de anuência. Conforme a resolução 510/2016 do Conselho Nacional de Saúde, foram respeitados os aspectos éticos, que regulamentam os estudos que envolvem os seres humanos, garantindo respeito, autonomia e defesa de sua vulnerabilidade contra riscos e danos. Assegurou-se a integridade e dignidade dos participantes da pesquisa, bem como a privacidade e confidencialidade no manejo das informações. Assim, o estudo foi aprovado pelo Comitê de Ética em Pesquisa (COEP) da Universidade do Vale do Taquari - UNIVATES sob o Parecer № 3.983.776.

Para se obter as informações necessárias, optou-se, como técnica de coleta de dados, pela entrevista semiestruturada, que propõe a utilização de um roteiro previamente elaborado, auxiliando na condução da entrevista. O roteiro de perguntas foi elaborado a partir das dimensões de fatores de risco psicossocial proposto por Veloso Neto (2015).

O local onde ocorreram as entrevistas foi um escritório corporativo, alugado pelo pesquisador, pois entendeu-se que essa condição asseguraria a neutralidade e a espontaneidade dos entrevistados. As entrevistas foram realizadas conforme interesse e disponibilidade dos participantes, fora do seu horário de trabalho, tiveram duração média de 40 minutos, foram gravadas com a autorização dos sujeitos envolvidos e, posteriormente, transcritas na íntegra. Antes de iniciar cada entrevista, foi realizada a leitura e posterior assinatura do Termo de Consentimento Livre e Esclarecido (TCLE).

Dentre as diversas técnicas de análise de conteúdo, optou-se pela análise temática ou categorial (Bardin, 2010), que consiste em identificar os núcleos de sentido que compõem a mensagem (conteúdo). A presença ou frequência de manifestação dos núcleos de sentido no texto podem sustentar algum significado para o objetivo do trabalho realizado.

Os dados geraram três categorias criadas $a$ posteriori conforme frequência das informações, ou seja, elaboradas após a análise do material: Sentidos do trabalho; Fatores psicossociais laborais (desta categoria, derivaram as subcategorias Conteúdo e organização do trabalho; Ritmos e tempos de trabalho; Liderança e avaliação de desempenho); e Fatores de proteção.

\section{Análise de Resultados}

Os fatores psicossociais têm o potencial de influir de maneira decisiva no bem-estar físico e mental do trabalhador, pois podem ocasionar uma diminuição do nível de saúde do ser humano. Esses fatores de risco nunca se apresentam no entorno do meio ambiente laboral isoladamente, mas se interatuam de forma a potencializar os efeitos nocivos (Perone \& Penido, 2013). É a partir dessa concepção que se sustenta a presente análise, conforme categorias que seguem.

\section{Sentidos do Trabalho}

As falas recorrentes das entrevistas denotam que a maioria dos servidores que trabalham no setor de Vigiläncia Sanitária, embora tivessem optado em atuar na administração pública, não escolheram estar nesse setor, ou seja, foram indicados para trabalhar nessa área. Apesar disso, sentem-se realizados pelas atividades que desenvolvem, principalmente pelo fato de se tratar de um trabalho educativo que atinge um grande número de pessoas.

"Quando eu fui chamada no concurso, que eu passei em primeiro lugar, eu fui direto para a Vigilância, não havia a possibilidade de escolher ir para o setor $x$ ou $y^{\prime \prime}(E 4)$.

"[...] podemos fazer um trabalho educativo junto à população, de não ser apenas um trabalho punitivo, mas sim preventivo. Então, nesse sentido, o trabalho na vigilância é recompensador: de pensar que a gente vai estar fazendo a diferença nos serviços que são usados pelas pessoas da cidade. O trabalho da vigilância é de grande importância, e muito necessário para a população"(E2).

Conforme Morin (2001), o trabalho precisa possibilitar a união que há entre a realização das atividades e as respectivas consequências sociais que são geradas. Isso auxilia na constituição da identidade social, além de preservar a dignidade da pessoa. Isto 
é, essa esfera do trabalho assume a satisfação das pessoas colaborarem com a sociedade.

A autora enfatiza, ainda, que o trabalho tem significado quando o trabalhador perceba o mesmo como legítimo, útil e importante. Para que isso seja possível, o significado do trabalho diz respeito à capacidade das atividades desenvolvidas terem um efeito relevante e positivo em relação às outras pessoas, ou seja, impacto social, seja na esfera organizacional, como também social.

Outro aspecto relevante nas respostas foi o fato de se sentirem realizados pelas relações saudáveis e união entre os colegas. Percebe-se a presença de solidariedade e afetividade entre os integrantes da equipe, conforme retratam as falas:

"Amo fazer o que eu faço. Eu me sinto bem acolhida, me sinto bem porque todo mundo se ajuda. É legal, somos uma família lá dentro"(E1).

"A minha relação com os colegas e equipe é ótima, gosto de ir trabalhar principalmente pelo carinho que tenho por eles"(E3).

Cunha (2011) salienta que a satisfação e a vontade em trabalhar tem ligação com a troca que há entre os colegas. Sendo assim, o contentamento em relação ao trabalho não diz respeito apenas ao resultado dos serviços prestados, mas também nas afinidades que são desenvolvidas nesse ambiente.

Diante disso, o trabalho se torna mais prazeroso, mesmo quando se trata de tarefas com altos graus de complexidade. Esse cenário ocasiona um efeito estimulante, através do desenvolvimento de vínculos afetivos duradouros, promovendo a segurança e autonomia. Assim, é possível se desvincular de problemas, tais como sentimentos que promovam a solidão e o isolamento social.

\section{Fatores Psicossociais Laborais}

\section{Conteúdo e Organização do Trabalho}

No que diz respeito às principais dificuldades e desafios encontradas na profissão dos servidores entrevistados, foi citada a questão da burocracia envolvida nas atividades desenvolvidas, uma vez que ela exige muito envolvimento após as inspeções sanitárias. A burocracia envolve, por exemplo, lançar a produtividade no Sistema de Informação de Vigilância Sanitária do Rio Grande do Sul, emitir o licenciamento da empresa em questão, dar andamento no Expediente no sistema da Prefeitura, alimentar os controles internos através de planilhas, instaurar Processos Administrativos Sanitários.

Como refere Gil-Monte (2012), os riscos psicossociais provenientes da atividade laboral podem ser causados por deterioração ou disfunção das características da tarefa, como a falta de complexidade, monotonia e repetitividade. Neste sentido, Camelo (2008) aponta que a variedade de tarefas pelas quais os trabalhadores estão envolvidos possui relação direta com a satisfação no trabalho, visto que a pouca diversidade de tarefas são fontes de riscos psicossociais, podendo ocasionar adoecimentos, como depressão e crises de ansiedade.

Tolfo e Piccinini (2007) acrescentam que, no momento em que a atividade passa a ser burocrática e cotidiana, deixando de estimular o responsável por ela, há uma perda no sentido que o trabalho tem para os indivíduos.

Além disso, os entrevistados mencionam que os sistemas informatizados utilizados são precários e dificultam a emissão de relatórios automaticamente, bem como o controle das rotinas e demandas de trabalho. Isso faz com que os servidores invistam bastante tempo para alimentar os dados.

"É um trabalho que não rende, porque toda inspeção externa gera um trabalho burocrático que consome muito mais tempo"(E2).

"Se não fosse tão burocrático, poderiase fazer mais trabalho na rua que eu considero muito importante, mais importante inclusive que o burocrático"(E5).

"Os nossos sistemas são muito ruins. Havia um programa que achávamos muito ruim, e o que usamos hoje é muito pior. Ele não gera relatórios, então temos que passar todas as informações para o excel e fazer tudo manualmente. Então se alimenta um sistema da prefeitura, um sistema de protocolo e cada colega tem as suas planilhas onde a gente alimenta os nossos controles"(E4). 
Angerami e Camelo (2008) indicam que podem ser considerados riscos psicossociais os problemas que dizem respeito à falta de recursos e equipamentos de trabalho, pois isso faz com que as atividades consumam mais tempo para serem realizadas, além de ocasionar a ineficiência dos processos. Como consequência, isso pode gerar pressão, estresse, irritação e desgaste em quem executa as atividades.

Ademais, Coleta e Siqueira referem que as condições do ambiente laboral são responsáveis pelo bem-estar do trabalhador. Sendo assim, tornam-se indispensáveis os recursos e equipamentos necessários para que seja possível realizar um trabalho de qualidade, com motivação e eficiência.

A interferência política que acontece nas esferas do serviço público também se mostra como um fator estressor do trabalho dos entrevistados.

"A demanda de trabalho é muito grande. $E$ a gestão não quer ver isso, porque o fiscal autua a população e isso vai contra o que os políticos querem"(E6).

"O que mais me incomoda é o fato de que a gente vai nas empresas fazer a fiscalização conforme a lei e logo depois liga um vereador ou político incomodando e tirando satisfação do porque fomos lá atrapalhar a empresa e o empresário. Essa interferência política é horrivel"(E6).

Neste sentido, a autonomia do servidor é afetada, uma vez que há falta de liberdade quanto ao poder de decisão dos servidores e o feedback em relação ao trabalho desenvolvido.

De acordo com Morin (2001), o entusiasmo pelo trabalho é resultado das alternativas em tomar decisões e em desenvolver a liberdade. Dessa forma, a falta do exercício em tomar decisões que dizem respeito ao ambiente de trabalho interfere negativamente nos sentimentos de eficácia e competência das funções desenvolvidas. Isso tem influência direta na motivação dos trabalhadores.

Ainda no que diz respeito à liberdade dos servidores entrevistados para tomar decisões, as respostas remetem a uma autonomia limitada para conduzir as suas atividades, processos e tomar decisões, ou seja, o poder de decisão é restrito pois é necessário seguir o que consta nas normatizações: leis, decretos e portarias. Em casos onde a tomada de decisão trata-se de assuntos complexos, a equipe discute e toma a decisão em conjunto.

Cunha et al. (2012) ressaltam que a autonomia possibilita o prazer pelo trabalho, pois o trabalho flexível permite o exercício da inteligência, da criatividade e da inovação. Em compensação, a falta da mesma pode condicionar os trabalhadores ao sofrimento e ao desinteresse.

\section{Ritmos e Tempos de Trabalho}

Outro fator mencionado diz respeito à falta de pessoas no setor para darem conta de toda a demanda de trabalho, gerando sobrecarga laboral, sendo esse um fator estressor. Os participantes ainda relatam que a gestão da prefeitura não identifica essa demanda de trabalho acumulado por não exercer acompanhamento das atividades do setor ou por não reconhecer o valor do trabalho realizado.

"Existem muitos expedientes parados e essa montanha nas mesas só cresce e isso gera bastante aflição. É ruim não conseguir dar conta da demanda, isso causa frustração"(E2).

“A gestão não tem noção de tudo o que fazemos, processos, protocolos, demandas. Acham que não precisaria ter tanta gente na equipe, sendo que a demanda de trabalho é muito grande. Infelizmente só nós que estamos no setor conseguimos enxergar isso. Eles não estão enxergando ou não querem enxergar porque para eles, neste momento não é possível atender ou não é interessante atender"(E5).

Essa conjuntura remete à sobrecarga laboral. De acordo com Pumariega (2018), isso acontece quando as demandas de trabalho ultrapassam os recursos e as capacidades dos trabalhadores para conseguirem executar com sucesso os seus processos e as suas obrigações no tempo estabelecido pelos gestores. A autora destaca, ainda, que as elevadas demandas de trabalho, associadas ao número pequeno de funcionários, incentivam 
aos trabalhadores a exceder os seus limites mentais e físicos, acarretando danos à saúde. Além disso, as sobrecargas de trabalho podem colocar em risco as expectativas que os trabalhadores possuem em relação às funções que desenvolvem.

Em consequência, os trabalhadores sentemse desmotivados e esgotados, conforme a fala abaixo:

“O que a gente vê por aí são muitas pessoas cansadas e desestimuladas, porque a gestão não faz nenhuma forma de te estimular"(E7).

Esse panorama remete à exaustão emocional, que conforme Alves e Valeretto (2014), é descrita pela falta de encantamento e energia, através da sensação de que os recursos estão esgotados, além do sentimento por parte dos trabalhadores de aflição e decepção, em virtude de compreenderem que não possuem mais condições em empregar esforços para atenderam às demandas solicitadas.

Os autores enfatizam ainda que a exaustão emocional, decorrente da sobrecarga laboral, pode interferir na qualidade do trabalho, uma vez que este pode deixar de ser realizado com excelência quando há pouca disponibilidade de tempo para realizá-lo.

\section{Liderança e Avaliação de Desempenho}

Para evitar a sobrecarga laboral, é fundamental que os gestores acompanhem o trabalho desenvolvido pelos servidores. Silva e Fernandes (2018) salientam que a maneira como o líder se manifesta com a equipe é um fator determinante para que o ambiente seja agradável, de forma que os colaboradores sejam comprometidos e eficazes. Além disso, a forma como o líder se posiciona interfere na forma como os colaboradores sentem-se. Em contrapartida, a ausência dele pode aumentar os fatores estressores dos trabalhadores.

Osservidoresainda sinalizaram que se sentem desmotivados por não sentirem-se valorizados pela gestão, o que diminuiu a produtividade pela falta de estímulos que há para se trabalhar.

"Se a gestão nos valorizasse mais, o nosso trabalho renderia muito mais, porque nos sentiríamos motivados e valorizados"(E8).

"O fato de não se ter nenhuma forma de reconhecimento é um fator que cansa muito o funcionário, desestimula a motivação e a vontade de trabalhar. $\mathrm{E}$ o reconhecimento e a motivação é algo que a gestão pública não sabe fazer. É por isso, que tem muitos funcionários que fazem o feijão com arroz e deu"(E7)!

A relação com a gestão municipal é muito distante, o que é evidenciado pelos relatos que apontam que ela não acompanha o trabalho praticado pela Vigilância e não tem conhecimento da demanda de trabalho que está parada em virtude dos poucos funcionários lotados no setor.

"Os gestores precisam ver que o nosso setor é sufocado e que não é possível burlar e desviar a lei"(E2).

"Não me sinto reconhecida pelo meu trabalho pela gestão. O fato de não se ter nenhuma forma de reconhecimento é um fator que cansa muito o funcionário, desestimula a motivação e a vontade de trabalhar. E o reconhecimento e a motivação é algo que a gestão pública não sabe fazer. É por isso, que tem muitos funcionários que fazem o feijão com arroz e deu" (E7)!

Nesse sentido, Paschoal e Tamayo (2003) enfatizam que o trabalho precisa manifestar algumas propriedades para que seja estimulado o comprometimento e a motivação de quem o executa. Para tanto, são imprescindíveis o reconhecimento e o apoio. Isso se deve ao fato de estimular os sentimentos de vinculação e afiliação. Além disso, é pertinente enfatizar que a presença de atitudes que estimulem o reconhecimento é um fator que proporciona bem-estar aos trabalhadores.

Pereira e Tolfo (2017) complementam ainda que a prática de feedback é um direito do trabalhador e dever dos gestores, pois, além de tornar os trabalhadores cientes de seus desempenhos e respectiva evolução, propicia a regulação das atividades, fazendo com que o trabalho tenha mais sentido, além de despertar o senso de responsabilidade.

Nesse contexto, conforme exposto pelos servidores entrevistados, é importante salientar que há pouco feedback. E esse é um fato gerador de angústia, pois os servidores não sabem se estão 
fazendo um bom trabalho ou não, pois não há avaliação e ocorre pouco acompanhamento das atividades que desenvolvem por parte da gestão pública, sendo que alguns setores não parecem ser bem vistos. Isso acaba gerando descontentamento e, em consequência, os vínculos tornam-se frágeis ou conflituosos entre gestão e servidores.

"Chega um ponto que tu se irrita tanto com a gestão, que tu acaba fazendo feijão com arroz e o teu salário continua o mesmo, sendo que tu não se estressa mais com nada. Esse é o problema! Acontecem muitas situações que fazem a pessoa se desestimular do trabalho. O sistema começa a te corroer"(E6)!

"Eu também nunca recebi nenhum feedback por parte da gestão, no sentido de dizer "teu trabalho está bom, que legal", nem esse tipo de recebimento. Muito mais críticas, do que elogios. Porque diga-se de passagem, muitos governantes acreditam que a vigilância só atrapalha (E7)".

A questão do feedback não se vale apenas à gestão municipal, mas também a alguns coordenadores, que, de acordo com o que foi narrado, não se indispõem com os seus subordinados para não gerar uma relação conflituosa.

"Um grande problema que percebo, que deveria gerar reflexão é o fato de que muitos coordenadores e gestores públicos não querem se indispor com os colegas, através das avaliações de desempenho. Mas esse colega que está há 15 anos trabalhando daquele jeito atravessado continua assim porque nunca alguém quis se indispor com ele. Isso é o ruim do servidor público, bem ruim mesmo" (E2).

Segundo Pereira (2010), a avaliação de desempenho é imprescindível para qualquer tipo de gestão, tanto pública, como privada, pois propicia o crescimento pessoal e profissional dos colaboradores, evidenciando consequências construtivas. Ainda, através da avaliação de desempenho sincera, há ganhos e crescimento de ambos os lados, tanto por parte do avaliador, como também por parte do avaliado, uma vez que identificam as fragilidades que impeçam o desenvolvimento e aperfeiçoamento profissional. Assim, há um impacto positivo tanto na equipe, como na instituição.

\section{Fatores de Proteção}

Ainda, percebeu-se que o relacionamento entre colegas e chefia é muito boa, uma vez que as respostas em relação a isso foram muito homogêneas. Todos dizem se relacionar muito bem com a equipe, pois há sintonia na forma de conduzir as atividades. Em consequência das relações saudáveis, Identificouse também que a maior parte dos servidores não trocariam de setor, caso houvesse a possibilidade.

Tratando-se de suporte social no ambiente de trabalho, Paschoal et al. (2010) afirmam que os aspectos sociais das empresas influenciam de forma direta os afetos e a construção do bem-estar. Sendo que esse suporte pode ser responsável por amenizar momentos de estresse e por ocasionar experiências positivas durante as jornadas de trabalho. Assim, seja dos colegas e até mesmo da chefia, é um fator responsável pelas emoções vivenciadas pelos trabalhadores. Quando o suporte é positivo, ocorre o desenvolvimento dos potenciais, habilidades e esforços das atividades desenvolvidas.

"A minha relação com os colegas e equipe é ótima, gosto de ir trabalhar principalmente pelo carinho que tenho por eles. Eu e a coordenadora sempre tivemos uma conexão muito grande, somos amigas fora daqui e então poder trabalhar com ela é muito gratificante para mim. A equipe de hoje tem sintonia, Hoje eu não trocaria de trabalho, pretendo continuar na Vigilância"(E3).

"A minha relação com os meus colegas é muito tranquila, muito boa com todos, sem exceções até agora pelo menos. Tanto que eu tenho vínculos de amizade fora de trabalho com alguns colegas"(E5).

Merece destaque $\mathrm{o}$ fato de muitos servidores terem mencionado que é muito positivo o fato da equipe ser multiprofissional, composta por veterinário, nutricionista, farmacêutica, enfermeira, professores, pois as diferentes percepções que se têm, em função das variadas formações tornam o grupo repleto de conhecimento, facilitando a tomada de decisão em conjunto, pois há vários pontos de 
vista que facilitam os embasamentos na tomada de decisão em conjunto.

"O fato de sermos profissionais de áreas diferentes é muito positivo, porque a visão do outro é boa porque passamos a ver as coisas de forma mais abrangente e faz com que as nossas decisões sejam mais assertivas e isso enriquece muito o trabalho e o nosso setor. E eu penso que é por nós termos uma equipe multiprofissional que faz com que a nossa Vigilância seja referência e modelo na região"(E4).

Diante desse cenário, Jordão e Paranhos (2017) mencionam que a diversidade humana nas organizações é um fato social que, diante do crescimento da sociedade contemporânea, tem reflexo nos diversos ambientes organizacionais. Sendo assim, tornam-se necessárias novas perspectivas dos gestores, acerca das equipes multiprofissionais nos mesmos espaços de trabalho.

Os autores afirmam que há muitos benefícios no que diz respeito de equipes heterogêneas, que vão ao encontro do que dizem as falas dos profissionais entrevistados. Ou seja, a diversidade permite a análise das mais diversas situações sob diferentes ângulos, tornando mais fácil o processo de soluções originais e criativas. Além disso, merece destaque o fato de que profissionais de diferentes formações constroem ambientes sociais mais tolerantes, onde há o desenvolvimento da empatia e união, gerando, assim, parcerias, lealdade e fidelidade por parte do grupo. Como consequência, há o fomento de um clima organizacional que estimula o crescimento dos profissionais.

\section{Considerações Finais}

Este artigo propôs analisar os principais riscos psicossociais do contexto laboral de servidores públicos do Setor de Vigilância Sanitária de um município localizado no interior do RS. A partir dos resultados, foram criadas três categorias: Sentidos do trabalho; Fatores psicossociais laborais (incluindo as subcategorias Conteúdo e organização do trabalho; Ritmos e tempos de trabalho; Liderança e avaliação de desempenho) e Fatores de proteção.

O estudo mostrou que apesar de os servidores não terem escolhido atuar no setor de Vigilância Sanitária, sentem-se realizados pelo trabalho que realizam, especialmente porque há um grande número de pessoas que dependem dos resultados deste trabalho. Além disso, poucos trocariam de setor ou atividade, caso pudessem escolher. Todavia, foram identificados riscos psicossociais que requerem atenção.

Evidenciou-se que o excesso de burocracia é um fator que torna o trabalho desses profissionais estressante e desestimulante, pois interfere no ritmo em que é desempenhado. Da mesma forma, a deficiência dos equipamentos e dos sistemas informatizados utilizados retardam o resultado do trabalho, gerando insatisfação. Nesse sentido, torna-se relevante repensar maneiras de adequar e simplificar os processos, tornando-os menos complexos. Além disso, investimentos em equipamentos e informatização permitirá um melhor desempenho das atividades realizadas.

Não obstante, os relatos demonstram que os profissionais sofrem em virtude do número reduzido de pessoas que compõem a equipe, denotando sobrecarga laboral. Ainda, a gestão parece não estar ciente dessa demanda, bem como não valoriza o trabalho que é realizado. Como consequência, os servidores sentemse angustiados e desvalorizados. Nesse aspecto, fica evidente a necessidade de aproximação da gestão com os servidores, a fim de acompanhar as atividades desenvolvidas, compreender os processos de trabalho e verificar o ajustamento de tarefas a serem executadas ao número de trabalhadores da equipe. É possível que sejam identificadas necessidades de modificação da organização do trabalho e, assim, melhorar o ambiente de trabalho.

Também merece destaque que, além da autonomia limitada em virtude da legislação que precisa ser seguida à risca, a interferência política é um fenômeno que afeta a atuação dos servidores, gerando estresse e diminuindo de forma considerável a motivação em trabalhar. Mesmo em condições restritas, é importante avaliar possibilidades de realização do trabalho que permita a liberdade para tomar decisões. Há oportunidades evidenciadas, já que, diante de assuntos complexos, a equipe discute e toma a decisão em conjunto. Isso pode ser explorado. 
É importante salientar que, quando medidas preventivas precoces são adotadas em relação ao risco psicossocial, pode-se obter uma redução considerável nos custos econômicos e sociais, tanto para o trabalhador quanto para o empregador e órgãos públicos (Rojas et al., 2018). Ainda, ressaltase que os riscos psicossociais identificados dizem respeito a um grupo de profissionais cujas funções possuem importância para a comunidade local, em virtude do grau de responsabilidade e do contato que eles possuem junto aos mais diversos setores produtivos do município. Além disso, o órgão tem envolvimento com mais de 3 mil estabelecimentos que dependem da sua autorização para funcionar.

Como limitações do estudo, enfatiza-se que as evidências desta pesquisa são baseadas no relato de um grupo de trabalhadores, portanto não são passíveis de generalizações. Apesar disso, acredita-se que esta pesquisa reflete o que ocorre nos controles sociais dos municípios do Rio Grande do Sul, em relação ao desconhecimento do trabalho do SUS, do SUAS, e o excesso de burocracias. Assim, os resultados deste estudo dão visibilidade a esse importante tema e público-alvo. Além disso, poderão estimular outras pesquisas, já que a gestão e a população desconhecem a complexidade e as normativas do trabalho na vigilância sanitária.

\section{Contribuição}

Os pesquisadores declaram não haver conflitos de interesse.

\section{Referências}

Abrahão, J., Assmar, E. M. L., Cruz, R. M., Ferreira, M. C., Mendes, A. M., Mendonça, H., Neto, S. B. C., Paz, M. G. T., Tamayo, A., \& Tamayo, M. R. (2008). Estresse e cultura organizacional. Casa do Psicólogo.

Alves, L., Ferreira, M. C. \& Tostes, N. (2009). Gestão de qualidade de vida no trabalho (QVT) no serviço público federal: o descompasso entre problemas e práticas gerenciais. Psicologia: Teoria e Pesquisa, 25(3), 319-327.
Alves, D. F. \& Valeretto, F. A. (2014). Fatores desencadeantes do estresse ocupacional e da síndrome de burnout em enfermeiros. Saúde Física \& Mental, 3(2), 1-11.

Angerami, E. L. S. \& Camelo, S. H. H. (2008). Riscos psicossociais no trabalho que podem levar ao estresse: uma análise da literatura. Ciência, Cuidado e Saúde, 7(2), 234-240.

Assunção, A. Á. \& Oliveira Vilela, L. V. (2007). Trabalho emocional: o caso dos teleatendentes de uma central de atendimento. Cadernos de Psicologia Social do Trabalho, 10(2), 81-93.

Balassiano, M., Pimenta, R. D. C., \& Tavares, E. (2011). Estresse ocupacional na administração pública brasileira: quais os fatores impactantes?. Revista de Administração Pública, 45(3), 751-774.

Bardin, L. (2010). Análise de Conteúdo. Edições 70.

Barham, E. J. \& Sanjutá, G. (2005). Uma análise do equilíbrio trabalho e família no contexto brasileiro. Nucleus, 3(1), 1-10.

Baumann, A., Muijen, M., \& Gaebel, W. (Eds.). (2010). Mental Health and Well-being at the Workplace: Protection and inclusion in challenging times. Who Regional Office for Europe.

Calheiros, P. R. V., dal Castel-Schlindw, V. D. L., Nunez-Pumariega, Y. \& Pumariega-Torres, C. D. (2018). "Envelheci no trabalho de tanto estresse": um estudo de caso sobre estresse e sobrecarga no trabalho (original). Revista científica Olimpia, 15(47), 103-116.

Campos, I. C. M., Cruz, R. M., Rabuske, M. M., Serafim, A. C. (2012). Riscos psicossociais e incapacidade do servidor público: um estudo de caso. Psicologia: Ciência e profissão, 32 (3): 686-705.

Cardoso, E. M. (2014). Morbimortalidade relacionada ao trabalho no estado do Amazonas, Brasil, 2000-2011. Epidemiologia e Serviços de Saúde, 23, 143-153.

Cavazotte, F. D. S. C. N., Oliveira, L. B. D. \& Paciello, R. R. (2013). Antecedentes e consequências dos conflitos entre trabalho e família. Revista de administração contemporânea, 17(4), 418-437. 
Charão-Brito, L. \& Freitas, L. A. V. (2016).

Engajamento no trabalho: um estudo em profissionais multidisciplinares de saúde em um município da Região Sul. Revista Cesumar - Ciências Humanas e Sociais Aplicadas, 21(2), 407-419.

Coleta, J. A. D. \& Siqueira, M. M. M. (1989). Metodologia para investigação da qualidade de vida no trabalho. Arquivos Brasileiros de Psicologia, 41(3), 51-66.

Conselho Federal de Contabilidade. (2014). Pesquisa perfil do profissional da contabilidade 2012/13: 2013.

Costa, L. S., \& Santos, M. (2013). Fatores psicossociais de risco no trabalho: Lições aprendidas e novos caminhos. International Journal on Working Conditions, 05, 39-58.

Cunha, L. A. M. (2011). A satisfação laboral e o compromisso organizacional dos colaboradores de uma empresa de comércio e reparação automóvel [Dissertação de Mestrado, Universidade do Minho, Portugal].

Cunha, S. C. D. P. D., Moraes, R. D. D. \& Vasconcelos, A. C. L. (2012). Prazer no trabalho: o lugar da autonomia. Psicologia, Organizações e Trabalho, 12(2), 217-227.

Conselho Federal de Contabilidade. (2014). Pesquisa perfil do profissional da contabilidade 2012/13: 2013.

Decreto-Lei n.o 5.452, de 1으 de maio de 1943. (1943, 9 agosto). Aprova a Consolidação das Leis do Trabalho. Presidência da República.

Domingues Junior, L. R. P. (2005). O processo saúde-doença no serviço público e suas consequências ao Estado, ao cidadão e ao servidor. In Ministério da Saúde. Coletânea de textos da 3 a Conferência Nacional de Saúde do Trabalhador (pp. 118-119).

Durkheim, E. (1977). Da divisão do trabalho social. Martins Fontes.

Emílio, M., Teixeira, M., Nobre, M., Godinho, T. (Orgs.). (2003). Trabalho e cidadania ativa para as mulheres: desafios para as Políticas Públicas. Coordenadoria Especial da Mulher.
Ferraz, F. C. \& Segre, M. (1997). O conceito de saúde. Revista de Saúde Pública, 31(5), 538-542.

Feitosa, C. M. C. \& Lima, A. V. D. Q. (2016). Avaliação de desempenho no setor público: fatores críticos e oportunidades de melhoria. Anais do 16 Colóquio Internacional de Gestion Universitaria. $\mathrm{CIGU}$, Arequipa, Peru.

Ferreira, M. C., Mendonça, H., Porto, J., \& Zanini, D. S. (2012). Saúde, qualidade de vida e bem-estar: limites e interfaces teóricometodológicas. Saúde e bem-estar no trabalho: dimensões individuais e culturais, 11-33.

Gil, A., C. (2006). Como elaborar projetos de pesquisa. Atlas.

Gil-Monte, P. R. (2012). Riesgos psicosociales en el trabajo y salud ocupacional. Revista peruana de Medicina Experimental y Salud pública, 29(2), 237-241.

Guimarães, L. A. M. (2013). Fatores psicossociais de risco no trabalho. Anais do, 2, 12-14.

Hirata, H. H. H. (2015). Globalização, trabalho e gênero. Revista de Políticas Públicas, 9(1), 111-128.

Jacques, M. da G. C. (2003). Abordagens teóricometodológicas em saúde/doença mental \& trabalho. Psicologia \& Sociedade, 15(1), 97-116. https://dx.doi.org/10.1590/S010271822003000100006

Jordão, J., Paranhos, R. (2017). Diversidade humana em organizações: a perspectiva de líderes em uma instituição se ensino superior. Intervozes: trabalho, saúde, cultura, 2(1), 23-42.Kawai, R. M. (2017). Indicadores de desempenho em uma pequena empresa que adota um modelo de gestão baseado na confiança. Revista da Micro e Pequena Empresa, 11(1), 123.

Lakatos, E., M. \& Marconi, M., A. (2010). Fundamentos de metodologia científica. Atlas.

Limongi-França, A., C. \& Rodrigues, A., L. (2014). Stress e trabalho: uma abordagem psicossomática. Atlas.

Loureiro, H., Oliveira, A. P., Pereira, A. N., \& Pessoa, A. R. (2008). Burnout no trabalho. Revista de Enfermagem Referência, 2(7), 33-41.

Malhotra, N., K. (2006). Pesquisa de marketing: uma orientação aplicada. Bookman. 
Mancebo, D. \& Ribeiro, C. V. D. S. (2013). O servidor público no mundo do trabalho do século XXI. Psicologia: ciência e profissão, 33(1), 192-207.

Marcondes, P. C. B. (2016). Servidor Público: teoria e prática. Fórum.

Morin, E. M. (2001). Os sentidos do trabalho. Revista de administração de empresas, 41(3), 08-19.

Moscovici, F. (2011). Desenvolvimento interpessoal: treinamento em grupo. José Olympio.

Nardi, H. C., \& Ramminger, T. (2007). Modos de subjetivação dos trabalhadores de saúde mental em tempos de Reforma Psiquiátrica. Physis: Revista de Saúde Coletiva, 17, 265-287.

Organização Internacional do Trabalho. (2014). Meeting of experts on updating the list of occupational diseases. OIT.

Paschoal, T., Porto, J. B., \& Torres, C. V. (2010). Felicidade no trabalho: relações com suporte organizacional e suporte social. Revista de Administração Contemporânea, 14(6), 1054-1072.

Paschoal, T. \& Tamayo, A. (2003). A relação da motivação para o trabalho com as metas do trabalhador. Revista de Administração Contemporânea, 07, 33-54.

Penido, L. D. O., \& Perone, G. (2013). Saúde mental no trabalho: esclarecimentos metodológicos para juristas. In J. J. Ferreira \& L. de O. Penido (Coords.), Saúde mental no trabalho: coletânea do fórum de saúde e segurança no trabalho do Estado de Goiás (pp. 33-44). Cir Gráfica.

Pereira, E. A. R. (2010). O processo negocial na avaliação de desempenho dos servidores técnico-administrativos da Universidade Federal do Ceará na visão dos gestores: o caso da Superintendência de Recursos Humanos [Trabalho de Conclusão de Curso de Especialização, Universidade Federal do Rio Grande do Sul].

Pereira, E. F., \& Tolfo, S. T. R. (2017). Estudos sobre sentidos e significados do trabalho na psicologia: uma revisão das suas bases teóricoepistemológicas. Psicologia Argumento, 34(87), 302-317.
Piccinini, V. \& Tolfo, S. R. (2007). Sentidos e significados do trabalho: explorando conceitos, variáveis e estudos empíricos brasileiros. Psicologia \& Sociedade, 19, 38-46.

Rojas, D. M., Orellano, N., \& Palma, H. H. (2018). Riesgo psicosocial: tendencias y nuevas orientaciones laborales. Psicogente, 21(40), 532-544.

Silva, J. J., \& Fernandes, C. M. (2018). O papel do líder na gestão do absenteísmo no ambiente de trabalho. Anais do Encontro Toledo de Iniciação Científica Prof. Dr. Sebastião Jorge Chammé. Centro Universitário Antônio Eufrásio de Toledo de Presidente Prudente.

Silva, N. \& Tolfo, S. R. (2012). Trabalho significativo e felicidade humana: explorando aproximações. Psicologia Organizações e Trabalho, 12(3), 341-354.

Tamayo, A. (2002). Exaustão emocional no trabalho. Revista de Administração da Universidade de São Paulo, 37(2), 26-37.

Tunes, G. (2019, 24 de março). Diferença entre salários de funcionários públicos e privados cresce no país. Correio Braziliense. https:// www.correiobraziliense.com.br/app/ noticia/economia/2019/03/26/internas_ economia,745508/diferenca-entre-salarios-defuncionarios-publicos-e-privados-cresce-no. shtml

Vasques-Menezes, I. (2012). Saúde e bem-estar no trabalho: dimensões individuais e culturais. Casa do Psicólogo.

Veloso Neto, H. (2015). Estratégias organizacionais de gestão e intervenção sobre riscos psicossociais do trabalho. International Journal on Working Conditions, 9, 1-21.

Vergara, S. C. (2006). Projetos e relatórios de pesquisa. Atlas. 